\title{
ANALISIS STRATEGI BERSAING PERUSAHAAN BUS MENGGUNAKAN TEKNIK RANTAI MARKOV, GAME THEORY, DAN SHORT ROUTE MODELS
}

\author{
Strategy Analysis of Competing Bus Companies using Markov Chain \\ Technique, Game Theory, and Short Route Models
}

\author{
Ade Momon Subagyo ${ }^{1 *}$, Okky Jayadi ${ }^{1}$, Ajeng Chintawati Dewi ${ }^{1}$ \\ ${ }^{1}$ Program Studi Teknik Industri, Universitas Singaperbangsa Karawang, Jl. H. S. Ronggowaluyo, Telukjambe \\ Timur, Karawang 41361, Indonesia
}

Diterima: 6 Juni 2018 / Disetujui: 23 Juli 2018

\begin{abstract}
Terminal Klari that located in Kabupaten Karawang has a function as a temporary stop place for public vehicles to raise and lower passengers. PO Bus with Klari-Purwokerto route is the object of the research. The large number of $P O$ busses on this route causes loyalty of the passenger is decline. These observations were made on 6 PO Busses with Klari-Purwokerto route and with 6 attributes, there are price, service, facilities, ease of getting information, easy of getting tickets, and the travel time. The objective of the research is to determine the competitive strategies based on the analysis of the bus brand switching by bus passengers with Klari-Purwokerto route. This research utilizes a Markov chain, game theory, and short route models. The results of processing and analysis using Markov chain, obtained that the market share reached steady state in the 11th period with a yield of 16.09\% for Dedy Jaya, 29.35\% for Murni Jaya, 25.13\% for Sinar Jaya, 7.97\% for Pahala Kencana, 10.69\% for DMI, and 10.77\% for Dieng Indah. From game theory method the results of the game there are several alternative strategies for DMI Buses, such as improving the means of promotion and communication so the passengers can get information with easily about Bus DMI. The alternative route from the short route model is Klari Terminal - Tol Kranci / Pejagan - Bumi Ayu - Purwokerto, with a total distance of $304.7 \mathrm{~km}$.
\end{abstract}

Keywords: Passenger movement, Markov chain, game theory, short route models

\begin{abstract}
ABSTRAK
Terminal Klari yang berlokasi di Kabupaten Karawang memiliki fungsi sebagai tempat pemberhentian sementara bagi kendaraan umum untuk menaikkan dan menurunkan penumpang. Perusahaan Otobus (PO) Bus di Terminal Klari dengan rute Klari - Purwokerto adalah bagian yang diteliti. Banyaknya PO Bus pada rute ini menyebabkan loyalitas penumpang menurun. Pengamatan dilakukan terhadap 6 PO Bus rute Klari-Purwokerto dengan 6 atribut yang meliputi harga, pelayanan, fasilitas, kemudahan mendapatkan informasi, kemudahan mendapatkan tiket, dan waktu tempuh. Adapun metode yang digunakan adalah teknik rantai markov, game theory, dan short route model. Tujuan dari penelitian ini, yaitu untuk menentukan strategi bersaing berdasarkan analisis peralihan pemilihan merek bus (brand switching) oleh penumpang bus dengan rute Klari - Purwokerto. Berdasarkan hasil pengolahan data dengan menggunakan metode rantai markov diperoleh bahwa pangsa pasar mencapai steady state pada periode ke-11 dengan hasil sebesar 16.09\% untuk Dedy Jaya, 29.35\% untuk Murni Jaya, 25.13\% untuk Sinar Jaya, 7.97\% untuk Pahala Kencana, 10.69\% untuk DMI, dan 10.77\% untuk Dieng Indah. Sedangkan untuk metode game theory, dari hasil permainan terdapat beberapa alternatif strategi untuk Bus DMI, seperti memperbaiki sarana promosi maupun komunikasi agar penumpang bisa mendapatkan informasi dengan mudah mengenai Bus DMI. Alternatif rute yang ditawarkan dengan short route models adalah Terminal Klari - Tol Kranci/Pejagan Bumi Ayu - Purwokerto, dengan total jarak $304 \mathrm{~km}$.
\end{abstract}

Kata Kunci: Perpindahan pelanggan, markov chain, game theory, short route models

*email: ade.momon@unsika.ac.id 


\section{PENDAHULUAN}

\subsection{Latar Belakang}

Terminal diartikan sebagai pangkalan kendaraan bermotor umum yang digunakan untuk mengatur kedatangan atau keberangkatan, menaikkan dan menurunkan orang dan/atau barang, serta perpindahan moda angkutan (Kementerian Perhubungan Republik Indonesia, 2015). Berdasarkan definisi tersebut dapat diketahui bahwa Terminal memiliki peran penting dalam sistem transportasi, dan menjadi urat nadi dalam kehidupan. Oleh karena itu, setiap daerah setidaknya memiliki satu Terminal untuk mendukung kelancaran transportasi, salah satunya seperti Terminal Klari di Kabupaten Karawang Provinsi Jawa Barat.

Pada saat ini, dapat disadari bahwa Terminal Klari tidak pernah sepi dari penumpang yang hendak pergi ke luar kota, terutama yang menggunakan Bus. Hal ini memicu berbagai macam Perusahaan Otobus (PO) Bus untuk berlomba-lomba dalam memfasilitasi penumpang yang akan melakukan perjalanan, contohnya saja perjalanan dengan rute Klari - Purwokerto. Banyaknya PO Bus yang melayani rute tersebut menyebabkan turunnya tingkat loyalitas penumpang sebagai akibat dari terjadinya perpindahan penggunaan Bus dari satu PO ke PO yang lainnya.

Permasalahan yang dihadapi adalah adanya peralihan pemilihan merek bus (brand switching) menyebabkan salah satu PO Bus sepi dari penumpang. Oleh karena itu, perlu dilakukan analisis strategi agar PO Bus dapat bersaing untuk mempertahankan penumpang.

Analisis strategi dilakukan dengan menggunakan teknik rantai markov, game theory, dan short route models. Ketiga metode tersebut dipilih dan dikombinasikan agar dalam analisis strategi ini dapat diketahui jumlah peralihan merek (brand switching) yang terjadi, rekomendasi rute terpendek yang dapat ditempuh, serta alternatif-alternatif strategi yang dapat menjadi data pendukung dalam pengambilan keputusan.

Rantai Markov (markov chains) adalah suatu teknik matematika yang biasa digunakan untuk melakukan pemodelan (modelling) bermacam-macam sistem dan proses bisnis (Andry, 2015). Markov chain pertama kali dikenalkan oleh A. A. Markov, untuk memprediksi perilaku sistem yang membuat transisi dari satu state ke state yang lain (Rai, 2016). Pada markov chain ada yang disebut dengan matriks transisi. Matriks transisi adalah perilaku jangka panjang dari perjalanan acak yang diatur oleh sifat-sifat (seperti nilai eigen dan vector eigen) pada matrix associated to the walk atau matriks tertentu (Dieker dan Saliola, 2018). Pada teknik markov chain terdapat istilah steady state. Steady state adalah suatu kondisi pada periode tertentu di mana matriks probabilitas transisi sudah mencapai kondisi tetap atau equilibrium (Siswanto, 2007).

Game theory diciptakan untuk menangani kesepakatan berdasarkan intelligent interaction di antara aktor-aktor strategis. Model game theory terdiri dari satu set (minimal 2) pemain, strategi untuk setiap pemain, dan nilai payoff (Zhang et al., 2018). Game theory menyediakan alat dan konsep solusi untuk menganalisis situasi guna menentukan pilihan strategis untuk memenangkan payoff atau rewards yang diharapkan (Nisan et al., 2007). Secara konkret, game theory menyediakan kerangka kerja matematis yang secara eksplisit memodelkan prilaku strategis, interaksi serta menganalisis keputusan yang dihasilkan, membuatnya ideal untuk mengevaluasi berbagai kasus bisnis yang berbeda dari sudut pandang optimisasi ekonomi (Coninx, Deconinck dan Holvoet, 2018).

Short route model adalah salah satu model jaringan yang aplikasinya mencakup beberapa bidang, seperti perencanaan telekomunikasi, dan transportasi (Jahan dan Hasan, 2011). Shortest route adalah gagasan umum untuk menentukan rute terpendek dengan menghitung jarak terpendek kumulatif dari satu titik ke node tertentu (Taha, 2007). Short route betujuan untuk menemukan jalur tercepat, cara tercepat, dan masalah biaya terendah (Khan et al., 2016).

Penelitian ini dilakukan untuk menentukan strategi bersaing bagi setiap PO Bus Rute Klari - Purwokerto berdasarkan analisis terhadap peralihan pemilihan merek bus (brand switching) yang dilakukan oleh penumpang. Kontribusi yang diharapkan adalah hasil penelitian ini dapat dijadikan pertimbangan atau pun sebagai data pendukung dalam pengambilan keputusan yang akan dilakukan oleh pemilik Perusahaan Otobus dengan rute Klari - Purwokerto untuk menentukan strategi bersaing demi mempertahankan pangsa pasar.

\subsection{Ruang Lingkup Penelitian}

Penelitian dilakukan di Terminal Klari pada PO Bus dengan rute Klari - Purwokerto. Berdasarkan hasil wawancara yang dilakukan 
oleh peneliti, diketahui bahwa kriteria-kriteria atau atribut yang menjadi penyebab dari adanya peralihan pemilihan merek bus (brand switching) adalah harga, pelayanan, fasilitas, kemudahan mendapatkan informasi, kemudahan mendapatkan tiket, dan waktu tempuh. Maka dari itu, enam variabel tersebut dipilih karena memiliki keterkaitan untuk menjadi dasar penelitian dalam mengetahui strategi bersaing yang menjadi tujuan dari dilakukannya penelitian ini. Pada matriks permainan, PO Bus DMI dipilih sebagai pemain utama. Penentuan pemain utama ini dilakukan secara acak oleh peneliti

\section{METODOLOGI}

Terminal Klari terletak di Jalan Raya Klari, Kabupaten Karawang. Terminal Klari terdapat banyak PO Bus yang melayani perjalanan dengan rute Klari - Purwokerto. Penelitian dilakukan di Terminal Klari pada PO Bus dengan rute Klari - Purwokerto.

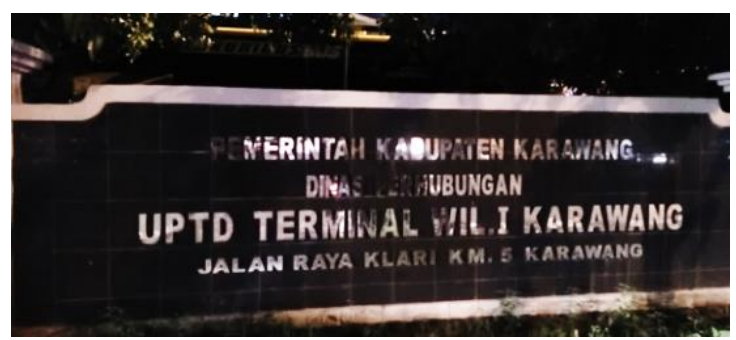

Gambar 1. Terminal Klari

Penelitian dilakukan pada tanggal $24-25$ November 2017. Pengambilan data dilakukan dengan cara pengamatan, wawancara, dan menyebarkan kuesioner (secara random) yang ditujukan kepada penumpang yang akan melakukan perjalanan menuju Purwokerto dari Terminal Klari. Adapun PO Bus yang melayani rute tersebut adalah sebanya $6 \mathrm{PO}$, yaitu $\mathrm{PO}$ Dedy Jaya, Murni Jaya, Sinar Jaya, Pahala Kencana, DMI, dan Dieng Indah. Po Bus tersebut ditunjukkan pada Gambar 2.

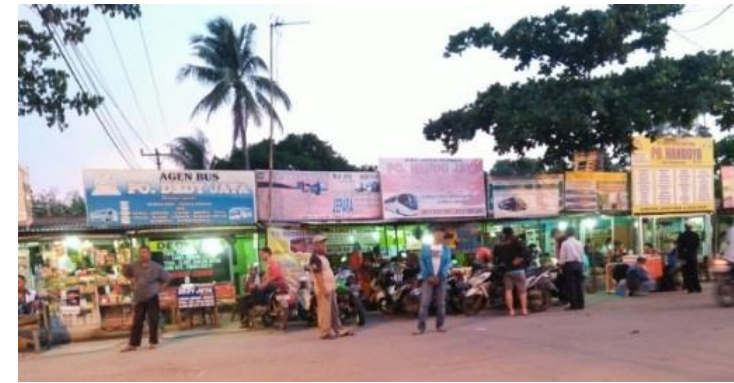

Gambar 2. PO Bus rute Klari - Purwokerto

Sebagai acuan dalam mempermudah penelitian dan proses pengumpulan serta pengolahan data, maka tahapan pelaksanaan penelitian yang dilakukan ditunjukkan pada Gambar 3.



Gambar 3. Tahapan Pelaksanaan Penelitian

\section{HASIL DAN PEMBAHASAN \\ 3.1. Metode Markov Chain}

Data yang dibutuhkan untuk mendukung dalam melakukan analisis dengan metode markov chain adalah data jumlah penumpang, data peralihan merek bus (brand switching), jumlah kehilangan, dan jumlah perolehan penumpang seperti yang ditunjukkan pada Tabel 1 sampai dengan Tabel 4.

Berdasarkan data tersebut maka representasi peralihan pemilihan merek pada penelitian ini dapat dimodelkan seperti yang ditunjukkan Gambar 4. 
Tabel 1. Jumlah Penumpang

\begin{tabular}{clcc}
\hline No & \multicolumn{1}{c}{ PO Bus } & Pengguna Saat Ini & Pangsa Pasar \\
\hline 1 & Dedy Jaya & 5 & 0.0704 \\
2 & Murni Jaya & 10 & 0.1408 \\
3 & Sinar Jaya & 21 & 0.2958 \\
4 & Pahala Kencana & 6 & 0.0845 \\
5 & DMI & 7 & 0.0986 \\
6 & Dieng Indah & 22 & 0.3099 \\
\hline & Total & $\mathbf{7 2}$ & $\mathbf{1 . 0 0 0 0}$
\end{tabular}

Sumber: Pengolahan Data (2018)

Tabel 2. Peralihan Pemilihan Merek Bus (Brand Switching)

\begin{tabular}{clcccc}
\hline No & \multicolumn{1}{c}{ PO Bus } & Jumlah Sebeumnya & Perolehan & Kehilangan & Jumlah Sekarang \\
\hline 1 & Dedy Jaya & 5 & 8 & 3 & 10 \\
2 & Murni Jaya & 10 & 13 & 6 & 17 \\
3 & Sinar Jaya & 21 & 11 & 14 & 18 \\
4 & Pahala Kencana & 6 & 5 & 5 & 6 \\
5 & DMI & 7 & 6 & 5 & 8 \\
6 & Dieng Indah & 22 & 4 & 14 & 12 \\
\hline & Total & 71 & 47 & 47 & \\
\hline
\end{tabular}

Sumber: Pengolahan Data (2018)

Tabel 3. Jumlah Kehilangan Penumpang dari PO Bus- $i$ ke PO Bus- $j$

\begin{tabular}{clccccccc}
\hline NO & \multicolumn{1}{c}{ PO Bus } & DJ & MJ & SJ & PK & DMI & DI & Total \\
\hline 1 & Dedy Jaya (DJ) & - & 2 & 1 & - & - & - & 3 \\
2 & Murni Jaya (MJ) & 1 & - & 2 & 1 & 1 & 1 & 6 \\
3 & Sinar Jaya (SJ) & 2 & 7 & - & 1 & 2 & 2 & 14 \\
4 & Pahala Kencana (PK) & 1 & 1 & 2 & - & 1 & - & 5 \\
5 & DMI (DMI) & 1 & - & 2 & 1 & - & 1 & 5 \\
6 & Dieng Indah (DI) & 3 & 3 & 4 & 2 & 2 & - & 14 \\
\hline & Total & 8 & 13 & 11 & 5 & 6 & 4 & 47 \\
\hline
\end{tabular}

Sumber: Pengolahan Data (2018)

Tabel 4. Jumlah Perolehan Penumpang PO Bus- $i$ ke PO Bus- $j$

\begin{tabular}{clccccccc}
\hline No & \multicolumn{1}{c}{ PO Bus } & DJ & MJ & SJ & PK & DMI & DI & Total \\
\hline 1 & Dedy Jaya (DJ) & - & 1 & 2 & 1 & 1 & 3 & 8 \\
2 & Murni Jaya (MJ) & 2 & - & 7 & 1 & - & 3 & 13 \\
3 & Sinar Jaya (SJ) & 1 & 2 & - & 2 & 2 & 4 & 11 \\
4 & Pahala Kencana (PK) & - & 1 & 1 & - & 1 & 2 & 5 \\
5 & DMI (DMI) & - & 1 & 2 & 1 & - & 2 & 6 \\
6 & Dieng Indah (DI) & - & 1 & 2 & - & 1 & - & 4 \\
\hline & Total & 3 & 6 & 14 & 5 & 5 & 14 & 47 \\
\hline
\end{tabular}

Sumber: Pengolahan Data (2018)

Tabel 5. Pola Peralihan Pemilihan Merek Bus (Brand Switching) dari PO Bus- $i$ ke PO Bus- $j$

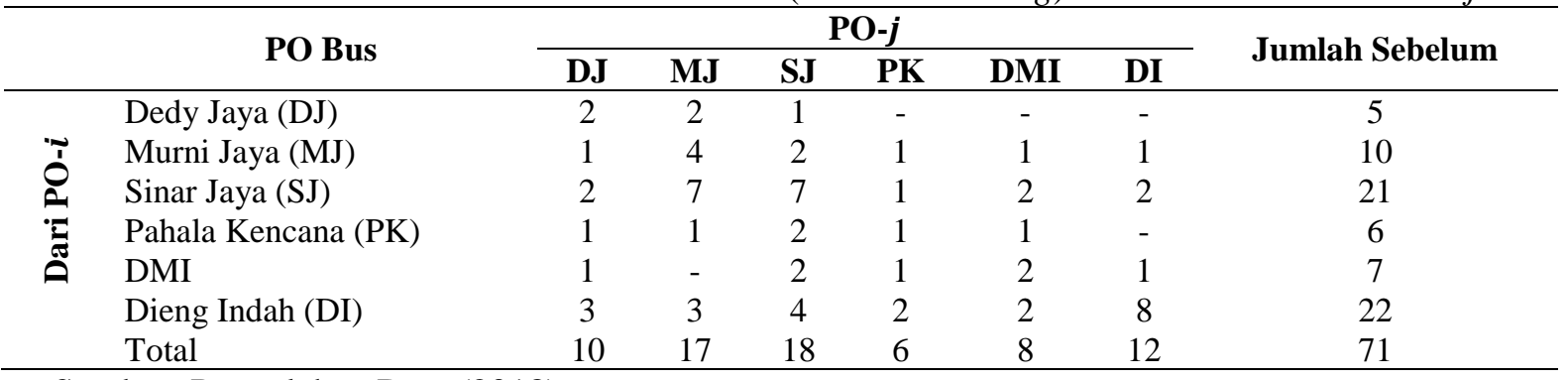

Sumber: Pengolahan Data (2018) 




Gambar 4. Representasi Peralihan Merek Bus (Brand Switching)

Sumber: Pengolahan Data (2018)

Nilai pada Tabel 5 digunakan untuk menghitung probabilitas transisi, yaitu:

$$
P=\left[\begin{array}{cccccc}
\frac{2}{5} & \frac{2}{5} & \frac{1}{5} & \frac{0}{5} & \frac{0}{5} & \frac{0}{5} \\
\frac{1}{10} & \frac{4}{10} & \frac{2}{10} & \frac{1}{10} & \frac{1}{10} & \frac{1}{10} \\
\frac{2}{21} & \frac{7}{21} & \frac{7}{21} & \frac{1}{21} & \frac{2}{21} & \frac{2}{21} \\
\frac{1}{6} & \frac{1}{6} & \frac{2}{6} & \frac{1}{6} & \frac{1}{6} & \frac{0}{6} \\
\frac{1}{7} & \frac{0}{7} & \frac{2}{7} & \frac{1}{7} & \frac{2}{7} & \frac{1}{7} \\
\frac{3}{22} & \frac{3}{22} & \frac{4}{22} & \frac{2}{22} & \frac{2}{22} & \frac{8}{22}
\end{array}\right]
$$

$P=\left[\begin{array}{llllll}0.4000 & 0.4000 & 0.2000 & 0.0000 & 0.0000 & 0.0000 \\ 0.1000 & 0.4000 & 0.2000 & 0.1000 & 0.1000 & 0.1000 \\ 0.0952 & 0.3333 & 0.3333 & 0.0476 & 0.0952 & 0.0952 \\ 0.1667 & 0.1667 & 0.3333 & 0.1667 & 0.1667 & 0.0000 \\ 0.1429 & 0.0000 & 0.2857 & 0.1429 & 0.2857 & 0.1429 \\ 0.1364 & 0.1364 & 0.1818 & 0.0909 & 0.0909 & 0.3636\end{array}\right]$

Berikut ini perhitungan untuk mendapatkan nilai market share, yaitu:

$$
\begin{aligned}
& P_{1(1)}=\frac{5}{71}=0.070423 \\
& P_{2(1)}=\frac{10}{71}=0.140845 \\
& P_{3(1)}=\frac{21}{71}=0.295775 \\
& P_{4(1)}=\frac{6}{71}=0.084507 \\
& P_{5(1)}=\frac{7}{71}=0.098592 \\
& P_{6(1)}=\frac{22}{71}=0.309859
\end{aligned}
$$

Berdasarkan perhitungan di atas, dapat diperoleh market share periode pertama [ $\pi(1)]$, yaitu:

$\left[\begin{array}{llllll}0.0704 & 0.1408 & 0.2958 & 0.0845 & 0.0986 & 0.3099\end{array}\right]$

Probabilitas transisi dan market share dapat digunakan untuk menghitung peluang transisi n-step dan steady state. Steady state diperoleh pada periode ke-11, yaitu:

1. Dedy Jaya menguasai pangsa pasar sebesar $16.09 \%$; 
2. Murni Jaya menguasai pangsa pasar sebesar 29.35\%;

3. Sinar Jaya menguasai pangsa pasar sebesar 25.13\%;

4. Pahala Kencana menguasai pangsa pasar sebesar $7.97 \%$;

5. DMI menguasai pangsa pasar sebasar $10.69 \%$;

6. Dieng Indah menguasai pangsa pasar sebesar $10.77 \%$.

\subsection{Menghitung Probabilitas Market Share dengan WinQSB}

Selain dengan perhitungan manual, kebenaran nilai steady state pada kasus peralihan pemilihan merek Bus rute Klari Purwokerto dibuktikan dengan penggunaan aplikasi WinQSB (Gambar 8, dan 9).

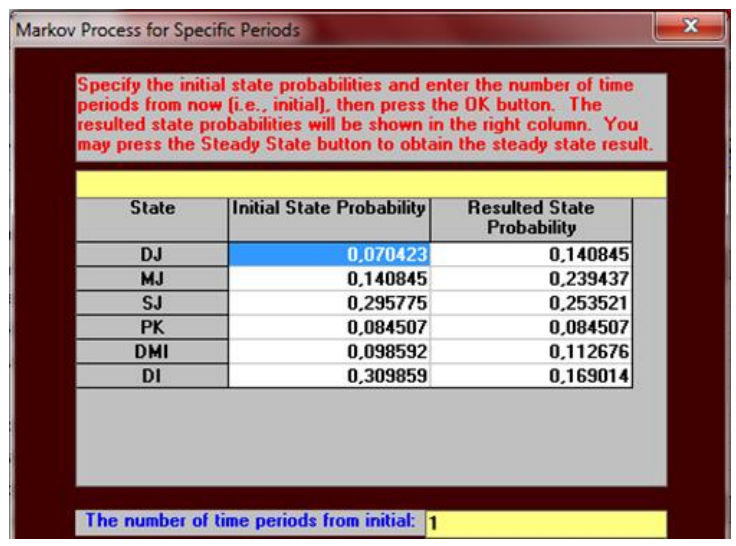

Gambar 7. Periode-1

Sumber: Pengolahan Data (2018)

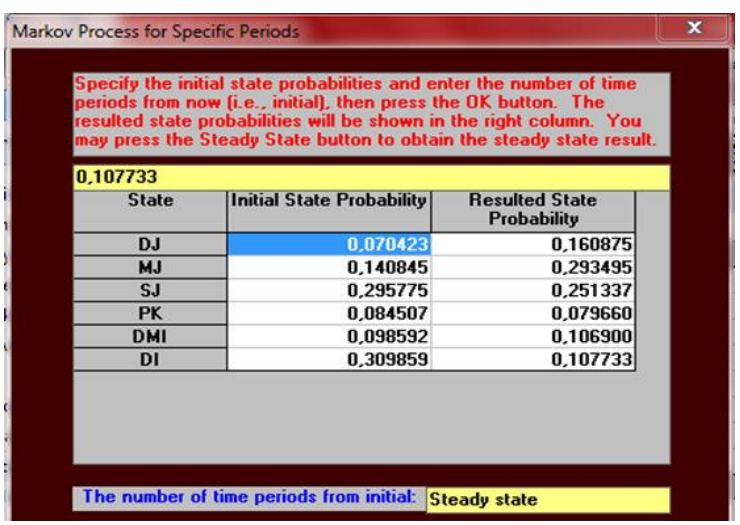

Gambar 8. Steady State dengan WinQSB

Sumber: Pengolahan Data (2018)

\subsection{Game Theory}

Analisis Game Theory dilakukan dengan cara pengumpulan data berupa penilaian responden terhadap atribut PO Bus. Data yang diperoleh ditunjukkan pada Tabel 6 dan Tabel 7 .
Tabel 6 Atribut PO Bus

\begin{tabular}{cl}
\hline Kode & \multicolumn{1}{c}{ Atribut } \\
\hline A1 & Harga tiket \\
A2 & Fasilitas \\
A3 & Pelayanan \\
A4 & Kemudahan mendapatkan tiket \\
A5 & Kemudahan mendapatkan informasi \\
A6 & Waktu tempuh \\
\hline
\end{tabular}

Sumber: Pengolahan Data (2018)

Tabel 7. Akumulasi Score

\begin{tabular}{ccccccc}
\hline PO & A1 & A2 & A3 & A4 & A5 & A6 \\
\hline SJ & 83 & 77 & 75 & 72 & 61 & 87 \\
DMI & 25 & 27 & 29 & 26 & 24 & 25 \\
DJ & 20 & 19 & 15 & 20 & 13 & 14 \\
MJ & 46 & 36 & 40 & 31 & 30 & 37 \\
PK & 24 & 24 & 27 & 20 & 21 & 25 \\
DI & 86 & 99 & 94 & 80 & 78 & 72
\end{tabular}

Sumber: Pengolahan Data (2018)

Adapun langkah-langkah yang dilakukan dalam game theory ini, yaitu:

1. Uji kecukupan data

Uji kecukupan data dilakukan dengan menyebar kuesioner kepada penumpang Bus rute Klari - Purwokerto. Kemudian dihitung jumlah responden yang mengisi kuesioner dengan benar dan yang tidak benar. Dari 72 responden hanya 71 responden yang mengisi kuesioner dengan benar, dan lengkap, maka proporsi kesuksesan subyek dalam mengisi kuesioner adalah $p=0.986$, sehingga didapat $q=0.014$ dengan tingkat signifikasi $95 \%(\mathrm{Z}=$ 1.96). Dari data yang ada, langkah selanjutnya adalah menguji kecukupan data dari kuesioner dengan menggunakan rumus Bernoulli seperti ditunjukkan pada rumus (1):

$$
\begin{gathered}
N=\left(\frac{Z_{\alpha / 2}}{e}\right)^{2} p \cdot q \\
N=\left(\frac{1.96}{0.05}\right)^{2}(0.986) .(0.014)=21.045
\end{gathered}
$$

Berdasarkan perhitungan, dapat diketahui bahwa jumlah minimal dari sampel adalah sebanyak 21 responden. Karena nilai N lebih kecil dari pada $71(\mathrm{~N}<71)$ maka dapat disimpulkan bahwa data mencukupi.

\section{Uji validitas dan reliabilitas}

Pada penelitian ini, pengujian validitas dilakukan dengan tingkat signifikasi 95\%. Dari 71 responden maka diketahui nilai $r$ pada tabel adalah 0.2335 . Uji validitas dengan perhitungan 
manual dapat dilakukan dengan menggunakan rumus (2), dan data pada Tabel 8. yang hasilnya kemudian ditunjukkan oleh Tabel 9.

$$
r=\frac{N\left(\sum X Y\right)-\left(\sum X \sum Y\right)}{\sqrt{\left[N \sum X^{2}-\left(\sum X\right)^{2}\right]\left[N \sum Y^{2}-\left(\sum Y\right)^{2}\right]}}
$$

Tabel 8. Nilai dari atribut

\begin{tabular}{ccccc}
\hline Atribut & $\sum \boldsymbol{x}_{\boldsymbol{i}}$ & $\sum \boldsymbol{x}_{\boldsymbol{i}}{ }^{2}$ & $\left(\sum \boldsymbol{x}_{\boldsymbol{i}}\right)^{\mathbf{2}}$ & $\sum \boldsymbol{x}_{\boldsymbol{i}} \boldsymbol{y}$ \\
\hline A1 & 284 & 1198 & 80656 & 6365 \\
A2 & 282 & 1190 & 79524 & 6321 \\
A3 & 280 & 1192 & 78400 & 6297 \\
A4 & 249 & 985 & 62001 & 5620 \\
A5 & 227 & 801 & 51529 & 5135 \\
A6 & 260 & 1038 & 67600 & 5834 \\
\hline
\end{tabular}

Sumber: Pengolahan Data (2018)
Tabel 9. Hasil Uji Validitas

\begin{tabular}{cccc}
\hline Atribut & $\boldsymbol{r}$ tabel & $\boldsymbol{r}$ hitung & Ket. \\
\hline A1 & 0.2335 & 0.26171652 & Valid \\
A2 & 0.2335 & 0.25015877 & Valid \\
A3 & 0.2335 & 0.34555472 & Valid \\
A4 & 0.2335 & 0.37860856 & Valid \\
A5 & 0.2335 & 0.49477854 & Valid \\
A6 & 0.2335 & 0.24496323 & Valid \\
\hline
\end{tabular}

Sumber: Pengolahan Data (2018)

Sebagai pembanding hasil yang diperoleh dari pengolahan data secara manual, maka digunakan perangkat lunak SPSS 16.0 dengan hasil yang ditunjukkan pada Gambar 9.

\begin{tabular}{|c|c|c|c|c|c|c|c|c|}
\hline & & $\times 1$ & $\times 2$ & $\times 3$ & $\times 4$ & $\times 5$ & $x_{6}$ & Total \\
\hline \multirow[t]{3}{*}{$\overline{X 1}$} & Pearson Correlation & 1 & -.061 & -.108 & .024 & -.117 & -.096 & $.262^{\prime}$ \\
\hline & Sig. (2-tailed) & & .615 & .368 & .842 & .331 & 426 & .027 \\
\hline & $N$ & 71 & 71 & 71 & 71 & 71 & 71 & 71 \\
\hline \multirow[t]{3}{*}{$\times 2$} & Pearson Correlation & -.061 & 1 & -.078 & $-.271^{\prime}$ & .130 & -.099 & $250^{\circ}$ \\
\hline & Sig. (2-tailed) & .615 & & .518 & .022 & .282 & .411 & .035 \\
\hline & $N$ & 71 & 71 & 71 & 71 & 71 & 71 & 71 \\
\hline \multirow[t]{3}{*}{$\times 3$} & Pearson Correlation & -.108 & -.078 & 1 & -.070 & .022 & -.119 & $346^{\prime \prime}$ \\
\hline & Sig. (2-tailed) & .368 & .518 & & .560 & .855 & .322 & .003 \\
\hline & $N$ & 71 & 71 & 71 & 71 & 71 & 71 & 71 \\
\hline \multirow[t]{3}{*}{$\times 4$} & Pearson Correlation & .024 & $-.271^{\circ}$ & -.070 & 1 & .043 & -.151 & $.379^{\prime \prime}$ \\
\hline & Sig. (2-tailed) & .842 & .022 & .560 & & .725 & .208 & .001 \\
\hline & $N$ & 71 & 71 & 71 & 71 & 71 & 71 & 71 \\
\hline \multirow[t]{3}{*}{$\times 5$} & Pearson Correlation & -.117 & .130 & .022 & .043 & 1 & -.066 & $495^{\prime \prime}$ \\
\hline & Sig. (2-tailed) & .331 & .282 & .855 & .725 & & .587 & .000 \\
\hline & $N$ & 71 & 71 & 71 & 71 & 71 & 71 & 71 \\
\hline \multirow[t]{3}{*}{$\overline{X 6}$} & Pearson Correlation & -.096 & -.099 & -.119 & -.151 & -.066 & 1 & $245^{\prime}$ \\
\hline & Sig. (2-tailed) & .426 & .411 & .322 & .208 & .587 & & .039 \\
\hline & $N$ & 71 & 71 & 71 & 71 & 71 & 71 & 71 \\
\hline \multirow[t]{3}{*}{ Total } & Pearson Correlation & $.262^{\prime}$ & $.250^{\circ}$ & $.346^{\prime \prime}$ & $.379^{\prime \prime}$ & $495^{\prime \prime}$ & $.245^{\prime}$ & 1 \\
\hline & Sig. (2-tailed) & .027 & .035 & .003 & .001 & .000 & .039 & \\
\hline & $N$ & 71 & 71 & 71 & 71 & 71 & 71 & 71 \\
\hline
\end{tabular}

*. Correlation is significant at the 0.05 level (2-tailed).

*. Correlation is significant at the 0.01 level (2-tailed).

Sumber: Pengolahan Data (2018)

Gambar 9. Uji Validitas dengan SPSS 16.0

3. Matriks Permainan

Nilai matriks permainan dilakukan dengan cara mengambil salah satu PO yang akan menjadi pemain utama (P1), secara acak dipilih DMI. Berikut ini, matriks payoff dari PO Bus DMI dengan PO Bus yang lainnya (Tabel 10 sampai Tabel 14), yaitu:
Tabel 10. Matriks Payoff DMI dan Sinar Jaya

\begin{tabular}{ccccccc}
\hline P1/P2 & A1 & A2 & A3 & A4 & A5 & A6 \\
\hline A1 & -0.58 & -0.52 & -0.5 & -0.47 & -0.36 & -0.62 \\
A2 & -0.56 & -0.5 & -0.48 & -0.45 & -0.34 & -0.6 \\
A3 & -0.54 & -0.48 & -0.46 & -0.43 & -0.32 & -0.58 \\
A4 & -0.57 & -0.51 & -0.49 & -0.46 & -0.35 & -0.61 \\
A5 & -0.59 & -0.53 & -0.51 & -0.48 & -0.37 & -0.63 \\
A6 & -0.58 & -0.52 & -0.5 & -0.47 & -0.36 & -0.62 \\
\hline
\end{tabular}

Sumber: Pengolahan Data (2018) 
Nilai maksimin sama dengan nilai minmaks yaitu 0.58 pada Tabel 10, sehingga dapat disimpulkan bahwa permainan dimenangkan oleh Sinar Jaya dengan nilai payoff -0.58 . Strategi pertama yang bisa digunakan agar DMI bisa memperbaiki kekalahannya adalah menggunakan strategi A5 (kemudahan untuk mendapatkan informasi).

Tabel 11. Matriks Payoff DMI dan Dedy Jaya

\begin{tabular}{ccccccc}
\hline P1/P2 & A1 & A2 & A3 & A4 & A5 & A6 \\
\hline A1 & 0.05 & 0.06 & 0.10 & 0.05 & 0.12 & 0.11 \\
A2 & 0.07 & 0.08 & 0.12 & 0.07 & 0.14 & 0.13 \\
A3 & 0.09 & 0.10 & 0.14 & 0.09 & 0.16 & 0.15 \\
A4 & 0.06 & 0.07 & 0.11 & 0.06 & 0.13 & 0.12 \\
A5 & 0.04 & 0.05 & 0.09 & 0.04 & 0.11 & 0.10 \\
A6 & 0.05 & 0.06 & 0.10 & 0.05 & 0.12 & 0.11 \\
\hline
\end{tabular}

Sumber: Pengolahan Data (2018)

Tabel 11. menunjukkan matriks permainan antara DMI dan Dedy Jaya. Karena nilai maksimin sama dengan nilai minimaks maka dapat disimpulkan bahwa permainan dimenangkan oleh DMI dengan atribut A4 dan nilai payoff 0.09 .

Tabel 12. Matriks Payoff DMI dan Murni Jaya

\begin{tabular}{ccccccc}
\hline P1/P2 & A1 & A2 & A3 & A4 & A5 & A6 \\
\hline A1 & -0.21 & -0.11 & -0.15 & -0.06 & -0.05 & -0.12 \\
A2 & -0.19 & -0.09 & -0.13 & -0.04 & -0.03 & -0.10 \\
A3 & -0.17 & -0.07 & -0.11 & -0.02 & -0.01 & -0.08 \\
A4 & -0.20 & -0.10 & -0.14 & -0.05 & -0.04 & -0.11 \\
A5 & -0.22 & -0.12 & -0.16 & -0.07 & -0.06 & -0.13 \\
A6 & -0.21 & -0.11 & -0.15 & -0.06 & -0.05 & -0.12 \\
\hline
\end{tabular}

Sumber: Pengolahan Data (2018)

Berdasarkan Tabel 12. Permainan dimenangkan oleh Murni Jaya dengan nilai payoff -0.17 .

Tabel 13. Matriks Payoff DMI dan Pahala

\begin{tabular}{ccccccc}
\multicolumn{7}{c}{ Kencana } \\
\hline P1/P2 & A1 & A2 & A3 & A4 & A5 & A6 \\
\hline A1 & 0.01 & 0.01 & -0.02 & 0.05 & 0.04 & 0 \\
A2 & 0.03 & 0.03 & 0 & 0.07 & 0.06 & 0.02 \\
A3 & 0.05 & 0.05 & 0.02 & 0.09 & 0.08 & 0.04 \\
A4 & 0.02 & 0.02 & -0.01 & 0.06 & 0.05 & 0.01 \\
A5 & 0 & 0 & -0.03 & 0.04 & 0.03 & -0.01 \\
A6 & 0.01 & 001 & -0.02 & 0.05 & 0.04 & 0
\end{tabular}

Sumber: Pengolahan Data (2018)

Tabel 13 menunjukkan matriks permainan antara DMI dan Pahala Kencana.
Karena nilai maksimin sama dengan nilai minimaks maka dapat disimpulkan bahwa permainan dimenangkan oleh DMI dengan nilai 0.02, sehingga untuk memperkecil kekalahannya, Pahala Kencana bisa menggunakan strategi A3 (pelayanan) dan A6 (waktu tempuh). Jika Pahala Kencana menggunakan atribut waktu tempuh maka atribut terlemah dari DMI adalah kemudahan mendapatkan informasi.

Tabel 14. Matriks Payoff DMI dan Dieng Indah

\begin{tabular}{ccccccc}
\hline P1/P2 & A1 & A2 & A3 & A4 & A5 & A6 \\
\hline A1 & -0.61 & -0.74 & -0.69 & -0.55 & -0.53 & -0.47 \\
A2 & -0.59 & -0.72 & -0.67 & -0.53 & -0.51 & -0.45 \\
A3 & -0.57 & -0.70 & -0.65 & -0.51 & -0.49 & -0.43 \\
A4 & -0.60 & -0.73 & -0.68 & -0.54 & -0.52 & -0.46 \\
A5 & -0.62 & -0.75 & -0.70 & -0.56 & -0.54 & -0.48 \\
A6 & -0.61 & -0.74 & -0.69 & -0.55 & -0.53 & -0.47 \\
\hline
\end{tabular}

Sumber: Pengolahan Data (2018)

Berdasarkan Tabel 14. diketahui bahwa permainan antara DMI dan Dieng Indah dimenangkan oleh Dieng Indah dengan atribut A2 dan nilai payoff -0.70 .

\subsection{Short Route}

Pengumpulan data kuantitatif yang dilakukan untuk mendukung penelitian ini adalah berupa rute dan jarak yang diperoleh dari Google Maps dengan titik-titik pemberhentian sesuai hasil wawancara yang telah dilakukan kepada setiap Petugas PO Bus Jurusan Purwokerto di Terminal Klari. Adapun titik pemberhentian dan masing masing jarak tempuh dari setiap PO Bus seperti pada Tabel 15. dan Tabel 16.

Tabel 15. Urutan Titik Pemberhentian Bus

\begin{tabular}{cl}
$\begin{array}{c}\text { PO } \\
\text { Bus }\end{array}$ & \multicolumn{1}{c}{ Kota } \\
\hline DJ & $\begin{array}{l}\text { Tol Kranci/ Pejagan - Tegal - Banjar } \\
\text { Anyar - Slawi Ayu - Purwokerto } \\
\text { MJ } \\
\text { Tol Kranci/ Pejagan - Pekalongan - } \\
\text { Tumanggung - Purwokerto } \\
\text { Tol Kranci/ Pejagan- Tegal - Pemalang - } \\
\text { Plawi Ayu - Bumi Ayu - Purwokerto } \\
\text { PK } \\
\text { Tol Kranci Pejagan - Bumi Ayu - Aji } \\
\text { Barang - Wangon - Purwokerto } \\
\text { DMI } \\
\text { Tol Kranci/ Pejagan - Wangon - Jeruk } \\
\text { Legi - Cilacap - Purwokerto } \\
\text { Tol Kranci/ Pejagan - Bumi Ayu - Aji } \\
\text { Barang - Purwokerto }\end{array}$ \\
\hline
\end{tabular}

Sumber: Data Observasi (2018) 
Tabel 16. Titik Pemberhentian Bus

\begin{tabular}{cc}
\hline Simbol & Kota \\
\hline A & Terminal Klari \\
B & Tol Kranci / Pejagan \\
C & Tegal \\
D & Pekalongan \\
E & Bumi Ayu \\
F & Wangon \\
G & Pemalang \\
H & Banjar Anyar \\
I & Aji Barang \\
J & Slawi Ayu \\
K & Temanggung \\
L & Jeruk Legi \\
M & Cilacap \\
N & Purwokerto \\
\hline
\end{tabular}

Sumber: Data Observasi (2018)

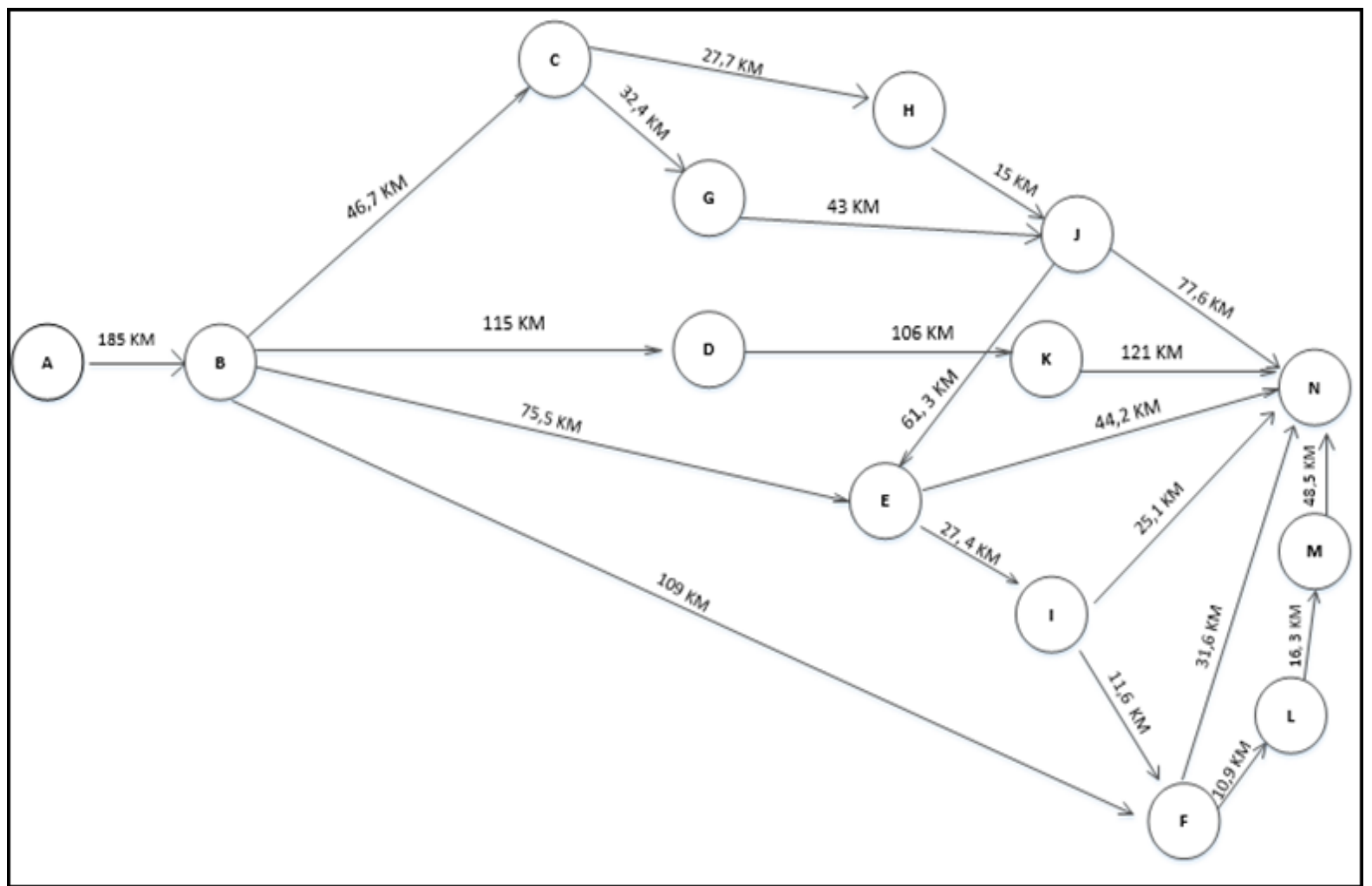

Sumber: Google Maps (25 April 2018)

Gambar 10. Jalur Bus menuju Purwokerto

Dengan data jarak yang diperoleh dari GoogleMaps, Gambar 10. menunjukkan rute yang dilalui oleh setiap Bus untuk bisa sampai ke Purwokerto. Perhitungan jarak ke titik tujuan difokuskan pada tempat yang mempunya jalur terpendek antara Terminal Klari sampai dengan Purwokerto. Berikut perhitungan lintasan terpendek untuk lintasan Bus jurusan Purwokerto menggunakan rumus (3).

$$
\left(\begin{array}{l}
\text { Shortest } \\
\text { Distance } \\
\text { to node } j
\end{array}\right)=\min _{i=2,3,4}\left\{\left(\begin{array}{c}
\text { Shortest } \\
\text { Distance } \\
\text { to node } i
\end{array}\right)+\left(\begin{array}{c}
\text { Disrance } \\
\text { from node } i \\
\text { to node } j
\end{array}\right)\right\}
$$

Stage 1

Berdasarkan Gambar 10 dapat dilihat bahwa jarak dari titk awal node A menuju node $\mathrm{B}$ adalah $185 \mathrm{~km}$. 
Stage 2

Pemilihan alternatif jalur untuk tujuan node selanjutnya dari node $\mathrm{B}$ memiliki beberapa alternatif tujuan node $(\mathrm{C}, \mathrm{D}, \mathrm{E}, \mathrm{F})$, yaitu:

$$
\begin{aligned}
\left(\begin{array}{l}
\text { shortest } \\
\text { distance } \\
\text { to node } j
\end{array}\right) & =\min _{i=2,3,4}\left\{\left(\begin{array}{l}
B \\
B \\
B \\
B
\end{array}\right)+\left(\begin{array}{l}
C \\
E \\
F \\
H
\end{array}\right)\right\} \\
\left(\begin{array}{l}
\text { shortest } \\
\text { distance } \\
\text { to node } j
\end{array}\right) & =\min _{i=2,3,4}\left\{\left(\begin{array}{l}
185 \\
185 \\
185 \\
185
\end{array}\right)+\left(\begin{array}{l}
46,7 \\
115 \\
75,5 \\
109
\end{array}\right)\right\} \\
& =\left(\begin{array}{c}
231.7 \\
300 \\
260.5 \\
294
\end{array}\right)
\end{aligned}
$$

Stage 3

Pemilihan alternatif jalur untuk tujuan node selanjutnya, yaitu $\mathrm{G}$ dan $\mathrm{H}$ memiliki satu alternatif tujuan yaitu node $\mathrm{C}$ :

$$
\begin{aligned}
\left(\begin{array}{l}
\text { shortest } \\
\text { distance } \\
\text { to node } j
\end{array}\right) & =\min _{i=2,3,4}\left\{\left(\begin{array}{l}
C \\
C
\end{array}\right)+\left(\begin{array}{l}
G \\
H
\end{array}\right)\right\} \\
\left(\begin{array}{l}
\text { shortest } \\
\text { distance } \\
\text { to node } j
\end{array}\right) & =\min _{i=2,3,4}\left\{\left(\begin{array}{l}
231.7 \\
231.7
\end{array}\right)+\left(\begin{array}{l}
32.4 \\
27.7
\end{array}\right)\right\} \\
& =\left(\begin{array}{l}
364.1 \\
259.4
\end{array}\right)
\end{aligned}
$$

Pemilihan alternatif jalur untuk tujuan node selanjutnya adalah $\mathrm{K}$ memiliki satu alternatif tujuan node yaitu node $\mathrm{D}$ :

$$
\begin{gathered}
\left(\begin{array}{c}
\text { shortest distance } \\
\text { to node } j
\end{array}\right)=\min _{i=2,3,4}\{(D)+(K)\} \\
\left(\begin{array}{c}
\text { shortest } \\
\text { distance } \\
\text { to node } j
\end{array}\right)=\min _{i=2,3,4}\{(300)+(106)\} \\
=(406)
\end{gathered}
$$

Pemilihan alternatif jalur untuk tujuan node selanjutnya adalah I memiliki satu alternatif tujuan node, yaitu node E:

$$
\left(\begin{array}{l}
\text { shortest } \\
\text { distance } \\
\text { to node } j
\end{array}\right)=\min _{i=2,3,4}\{(E)+(I)\}
$$

$$
\begin{aligned}
\left(\begin{array}{l}
\text { shortest } \\
\text { distance } \\
\text { to } \text { node } j
\end{array}\right)= & \min _{i=2,3,4}\{(260,5)+(27,4)\} \\
& =(287.9)
\end{aligned}
$$

Pemilihan alternatif jalur untuk tujuan node selanjutnya adalah $\mathrm{L}$ memiliki satu alternatif tujuan node, yaitu node $\mathrm{F}$ :

$$
\begin{aligned}
& \left(\begin{array}{c}
\text { shortest distance } \\
\text { to node } N
\end{array}\right)=\min _{i=2,3,4}\{(F)+(L)\} \\
& \left(\begin{array}{c}
\text { shortest distance } \\
\text { to node } N
\end{array}\right) \\
& =\min _{i=2,3,4}\{(294)+(10.9)\} \\
& =(304.9)
\end{aligned}
$$

Stage 4

Pemilihan alternatif jalur untuk tujuan node selanjutnya adalah $\mathrm{J}$ memiliki dua alternatif tujuan node, yaitu node $\mathrm{G}$ dan $\mathrm{H}$ :

$$
\begin{aligned}
\left(\begin{array}{l}
\text { shortest } \\
\text { distance } \\
\text { to node } j
\end{array}\right) & =\min _{i=2,3,4}\left\{\left(\begin{array}{l}
G \\
H
\end{array}\right)+\left(\begin{array}{l}
J \\
J
\end{array}\right)\right\} \\
\left(\begin{array}{l}
\text { shortest } \\
\text { distance } \\
\text { to node } j
\end{array}\right) & =\min _{i=2,3,4}\left\{\left(\begin{array}{l}
264.1 \\
259.4
\end{array}\right)+\left(\begin{array}{l}
43 \\
15
\end{array}\right)\right\} \\
& =\left(\begin{array}{l}
307,1 \\
274,4
\end{array}\right)
\end{aligned}
$$

Pemilihan alternatif jalur untuk tujuan node selanjutnya adalah $\mathrm{F}$ memiliki satu alternatif tujuan node, yaitu node I:

$$
\begin{aligned}
\left(\begin{array}{l}
\text { shortest } \\
\text { distance } \\
\text { to } \text { node } j
\end{array}\right) & =\min _{i=2,3,4}\{(I)+(F)\} \\
\left(\begin{array}{l}
\text { shortest } \\
\text { distance } \\
\text { to } \text { node } j
\end{array}\right) & =\min _{i=2,3,4}\{(287.9)+(11.6)\} \\
& =(299.5)
\end{aligned}
$$

Pemilihan alternatif jalur untuk tujuan node selanjutnya adalah $\mathrm{M}$ memiliki dua alternatif tujuan node yaitu node L:

$$
\left(\begin{array}{l}
\text { shortest } \\
\text { distance } \\
\text { to node } j
\end{array}\right)=\min _{i=2,3,4}\{(L)+(M)\}
$$




$$
\begin{aligned}
\left(\begin{array}{l}
\text { shortest } \\
\text { distance } \\
\text { to node } j
\end{array}\right)= & \min _{i=2,3,4}\{(304.9)+(16.3)\} \\
& =(321.2)
\end{aligned}
$$

Stage 5

Pemilihan alternatif jalur untuk tujuan node selanjutnya $\mathrm{N}$ memiliki satu alternatif tujuan node, yaitu node J, K, E, I, F, M:

$\left(\begin{array}{c}\text { shortest distance } \\ \text { to node } N\end{array}\right)=\min _{i=2,3,4}\left\{\left(\begin{array}{c}J \\ K \\ E \\ I \\ F \\ M\end{array}\right)+\left(\begin{array}{c}N \\ N \\ N \\ N \\ N \\ N\end{array}\right)\right\}$

$$
\begin{aligned}
\left(\begin{array}{c}
\text { shortest } \\
\text { distance } \\
\text { to node } \\
N
\end{array}\right)= & \min _{i=2,3,4}\left\{\left(\begin{array}{c}
274.4 \\
406 \\
260.5 \\
287.9 \\
294 \\
321
\end{array}\right)+\left(\begin{array}{c}
77.6 \\
121 \\
44.2 \\
25.1 \\
31.6 \\
48.5
\end{array}\right)\right\} \\
& =\left(\begin{array}{c}
304.7 \\
527 \\
304.7 \\
313 \\
325.6 \\
369.7
\end{array}\right)
\end{aligned}
$$

Berdasarkan lima tahap yang telah dijelaskan, diperoleh rute dengan lintasan terpendek yaitu $\mathrm{A} \rightarrow \mathrm{B} \rightarrow \mathrm{E} \rightarrow \mathrm{N}=304.7 \mathrm{~km}$ yang ditunjukkan pada Gambar 11.

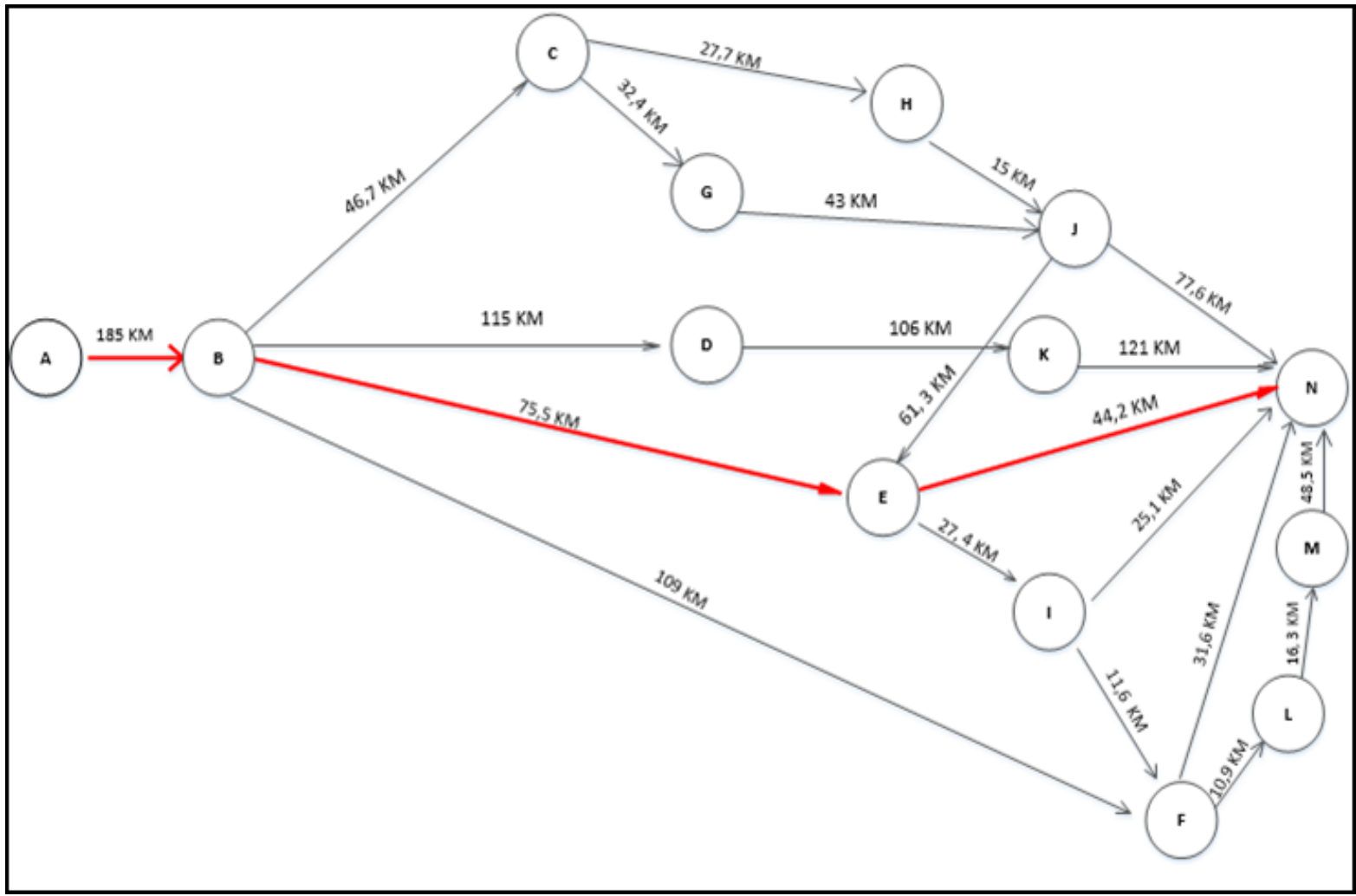

Sumber: Pengolahan Data (2018)

\section{Gambar 11. Rute TerpendekMenuju Purwokerto}

\section{SIMPULAN}

Berdasarkan pengolahan data yang dilakukan maka kesimpulannya, yaitu Murni Jaya memiliki market share terbesar diantara PO Bus yang lainnya, sebesar 29,35\%. Kemudian posisi kedua ditempati oleh Sinar Jaya $(25,13 \%)$, Dedy Jaya $(16,09 \%)$, Dieng Indah $(10,77 \%)$, DMI $(10,69 \%)$, dan Pahala Kencana $(7,97 \%)$.

Pengolahan data dengan game theory memberikan beberapa alternative strategi untuk
Bus DMI agar tetap bisa mempertahankan penumpangnya, seperti seperti memperbaiki sarana promosi maupun komunikasi agar calon penumpang bisa mendapatkan informasi dengan mudah mengenai Bus DMI.

Short route models menawarkan alternatif rute terpendek yang bisa ditempuh untuk menuju Purwokerto dari Terminal Klari, yaitu Terminal Klari - Tol Kranci/Pejagan - Bumi Ayu - Purwokerto, dengan total jarak 304.7 km. 


\section{DAFTAR PUSTAKA}

Andry, J. F. (2015) "Implementasi penerapan markov chain pada database marketing studi kasus pelanggan e-commerce," Jurnal Teknologi Informasi, 11(2), hal. 5-13.

Coninx, K., Deconinck, G. dan Holvoet, T. (2018) "Who gets my flex? An evolutionary game theory analysis of flexibility market dynamics," Applied Energy, 218, hal. 104-113. doi: 10.1016/j.apenergy.2018.02.098.

Dieker, A. B. dan Saliola, F. V. (2018) "Spectral analysis of random-to-random Markov chains," Advances in Mathematics. Elsevier Inc., 323, hal. 427-485. doi: 10.1016/j.aim.2017.10.034.

Jahan, S. dan Hasan, M. S. (2011) "A comparative study on algorithms for shortest-route problem and some extensions," International Journal of Basic and Applied Sciences, 11(6), hal. 167-177.

Kementerian Perhubungan Republik Indonesia (2015) Peraturan Menteri Perhubungan Republik Indonesia nomor PM 132 tentang penyelenggaraan terminal penumpang angkutan jalan. Republik Indonesia. Tersedia pada: http://jdih.dephub.go.id/produk_hukum /view/VUUwZ01UTXIJRIJCU0ZWT01 ESXdNVFU9.

Khan, S. Y. et al. (2016) "Establishment of the shortest route-a prototype for facilitation in road network," 5(9), hal. 41-44.

Nisan, N. et al. (2007) Algorithmic game theory. New York: Cambridge University Press.

Rai, P. (2016) "Google pagerank algorithm: markov chain model and hidden markov model," 138(9), hal. 9-13.

Siswanto (2007) Operations research. 2 ed. Jakarta: Erlangga.

Taha, H. A. (2007) Operations Research: An Introduction. 8 ed. New Jersey: Pearson Education.

Zhang, L. et al. (2018) "Integrating the API SRA methodology and game theory for improving chemical plant protection," Journal of Loss Prevention in the Process Industries. Elsevier, 51, hal. 816. doi: 10.1016/j.jlp.2017.11.002. 